\title{
COMPETÊNCIA EM TRADUÇÃO E LÍNGUAS DE SINAIS: A MODALIDADE GESTUAL-VISUAL E SUAS IMPLICAÇÕES PARA UMA POSSÍVEL COMPETÊNCIA TRADUTÓRIA INTERMODAL
}

\author{
TRANSLATION COMPETENCE AND SIGN LANGUAGES: THE \\ GESTURAL-VISUAL MODALITY AND ITS IMPLICATIONS TO A \\ POTENTIAL INTERMODAL TRANSLATION COMPETENCE
}

\section{Carlos Henrique Rodrigues*}

\section{RESUMO}

Neste artigo, oferecemos uma primeira reflexão sobre as prováveis implicações da modalidade de língua, no caso a gestual-visual, sobre a noção e a modelagem da competência tradutória. Para tanto, realizamos uma breve revisão de algumas definições e modelos de competência tradutória e apresentamos as características das línguas de modalidade gestualvisual, bem como seus impactos sobre a atuação dos tradutores/intérpretes de línguas de sinais. Vimos que considerar a modalidade gestual-visual na definição e modelagem da competência tradutória é uma questão extremamente complexa. Entretanto, é, ao mesmo tempo, relevante, já que as investigações nesse âmbito podem contribuir significativamente à melhor compreensão do que constituiria uma competência tradutória "universal" e, mais estritamente, do que comporia a competência dos tradutores e dos intérpretes de línguas de sinais. Concluímos que a competência requerida dos tradutores e intérpretes de línguas de sinais é marcada por certa capacidade corporal cinestésica, diretamente ligada à competência linguística e à competência comunicativa. E, portanto, poderia ser concebida como uma competência tradutória intermodal.

Palavras-chave: tradução; competência tradutória; língua de sinais.

\section{ABSTRACT}

In this paper, we offer a first thought about the possible implications of language modality, specifically the gestural-visual one, on the notion of translation competence and its modelling. To do so, we make a brief review of some already existing definitions and models of translation competence, and present the characteristics of the languages of gestural-visual modality, as well as their effect on the performance of sign language translators/interpreters. We have seen that it is very complex to apply the gestural-visual modality in the definition and modelling of the translation competence. However, it is a relevant issue, since the investigations in this scope can contribute significantly to the better understanding of what would constitute a "universal" translation competence, and, more specifically, of what would

\footnotetext{
* Universidade Federal de Santa Catarina, Florianópolis, SC, Brasil. carlos.rodrigues@ufsc.br
} 
compose the sign language translators/interpreters' competence. We conclude that the sign language translators' and interpreters' required competence is defined by a kinesthetic corporeal ability directly linked to linguistic and communicative competences. Therefore, such required competence can be conceived as an intermodal translation competence.

Keywords: translation; translation competence; sign language.

\section{INTRODUÇÃO}

Atualmente, podemos afirmar que há certo consenso, entre os estudiosos da tradução e da interpretação, sobre a complexidade do traduzir e, por sua vez, a necessidade de que tradutores e intérpretes tenham uma expertise que os diferencie dos demais bilíngues (SCHÄFFNER; ADAB, 2000). A investigação sobre qual seria essa expertise, que de fato distinguiria os tradutores/intérpretes dos demais, tem sido realizada, principalmente, sob o conceito de competência. E, com base nesse conceito, não muito consensual no âmbito das Ciências Humanas, alguns modelos elucidativos de competência tradutória têm sido construídos e manipulados.

Vale mencionar que, no contexto latino-americano, são escassas as propostas de modelagem da competência tradutória, bem como os estudos e reflexões sobre a pertinência e/ou aplicabilidade dos modelos já existentes. A maioria dos modelos reconhecidos e difundidos foram propostos por pesquisadores europeus e a única proposta com projeção mundial que encontramos desde a América Latina é o modelo apresentado pelo brasileiro José Luiz Gonçalves, da Universidade Federal de Outro Preto (GONÇALVES, 2005), e aperfeiçoado por ele junto ao também brasileiro, da Universidade Federal de Minas Gerais, Fábio Alves (ALVES, GONÇALVES, 2007). Além disso, embora seja possível encontrar textos de autores latino-americanos que remetem aos modelos de competência tradutória ou fazem uso deles, esses textos não propõem alterações ou atualizações aos modelos.

Partindo da premissa de que a competência do tradutor "é constituída de diferentes componentes ou subcompetências, que devem ser adequadamente articuladas para que o desempenho experto possa se manifestar" (GONÇALVES, 2008, p.124), todos esses modelos buscam identificar, basicamente, quais seriam os elementos que, em uma trama complexa, constituiriam a competência para traduzir/interpretar em termos de capacidades, habilidades, conhecimentos e/ou atitudes, por exemplo, que requerem processos de âmbitos cognitivos, biológicos e sociointerativos, como destaca Gonçalves $(2005,2008)$. Com exceção da proposta minimalista de Anthony Pym (2003), que se opõe diretamente aos demais, podem- 
se qualificar esses modelos, assim como o fazem Schäffner e Adab (2000), como componenciais, já que desmembram a competência em unidades inter-relacionadas.

Pensados para ilustrar os componentes desse tipo de competência, assim como seu caráter e funcionamento, esses modelos partem de uma abordagem geral da tradução interlinguística, sem dar conta de abarcar - ou mesmo sem a pretensão de abranger - a totalidade daquilo que distintos grupos de tradutores/intérpretes precisam dominar, em relação às suas demandas profissionais específicas e variáveis. Nessa perspectiva, observa-se que tais modelos abrangentes concentram-se, sobretudo, na tradução escrita, sem realizar uma reflexão mais apurada sobre outros tipos de processos tradutórios e/ou interpretativos, modalidades de tradução ou mesmo sobre processos que envolvam línguas de modalidade gestual-visual.

Considerando que os reconhecidos modelos de competência tradutória não fazem referência direta à tradução e/ou à interpretação envolvendo línguas de sinais, propomos uma primeira reflexão sobre como a questão da diferença de modalidade poderia trazer implicações a esses modelos. Portanto, partindo de uma revisão de alguns dos modelos de competência tradutória existentes e de uma abordagem dos possíveis efeitos de modalidade de língua sobre o processo tradutório/interpretativo, apresentamos as prováveis implicações que a modalidade de língua poderia ter na compreensão, explicação e funcionamento da competência tradutória, a qual, inclusive, poderia ser concebida, no nosso caso, como uma competência tradutória intermodal.

\section{A COMPETÊNCIA TRADUTÓRIA E SEUS MODELOS COMPONENCIAIS}

A abordagem da competência no campo disciplinar dos Estudos da Tradução tem sido conduzida por diferentes enfoques e, inclusive, sob diferentes noções e termos, tais como: habilidades de tradução (translation abilities/ translation skills); competência de transferência (transfer competence); competência do tradutor (translator competence); competência em tradução e competência tradutória (translational competence/translation competence), dentre outros. Na verdade, o vocábulo competência age como um hiperônimo, um termo guarda-chuva, um conceito integrador para se referir à capacidade geral de desempenho dos tradutores, a qual parece ser tão difícil de definir (SCHÄFFNER; ADAB, 2000).

Independente da abordagem ou do enfoque posto sobre o conceito e/ou o estudo da competência tradutória em toda a sua complexidade, heterogeneidade e diversidade, temos que considerar de antemão que ela seria um saber especializado, um tipo de expertise, composto por diferentes elementos, os quais de maneira integrada 
e indissociável qualificariam, distinguiriam e singularizariam o(s) indivíduo(s) tradutor(es)/intérprete(s) em relação aos demais. Além disso, é importante considerar que esse tipo de competência "é uma habilidade adquirida que passa por diferentes fases, evoluindo de conhecimento novato a conhecimento experto". (KEY CONCEPTS; MUNDAY, 2009, p. 234-5, tradução minha).

Ao discutir o conceito de competência, a partir de dez diferentes definições propostas entre 1990 e 2015, Basque (2015) afirma que, embora a noção de competência suscite diversos debates no meio acadêmico, existiria certa uniformidade na maneira de defini-la, a qual pode ser expressa a partir das seguintes recorrências encontradas em suas descrições como: (i) um saber-agir; (ii) um saberagir contextualizado; (iii) um saber-agir que requer a mobilização de recursos; (iv) um saber-agir que se manifesta em uma performance. Some-se a estes, o fato de que a competência, como destaca Gonçalves (2008, p. 127), caracteriza-se

pela constituição de rotinas cognitivas e sensório-motoras que: (1) derivam da estrutura biológica do indivíduo e do conjunto de interações entre este indivíduo e seu meio; e (2) produzem um conjunto de comportamentos historicamente situados e sócio-culturalmente valorizados. Logo, uma competência se constrói a partir de padrões sócio-culturais e históricos, os quais se organizam e se estruturam cognitivamente a partir de restrições biológicas e do histórico de interações vivenciadas. Ou seja, ao lidarmos com questões relativas à competência, não há como ignorar a estreita vinculação e complementaridade entre esses dois domínios.

Particularmente, em relação ao conceito de competência tradutória, podemos recorrer a algumas definições encontradas no campo dos Estudos da Tradução, as quais diferenciam essa competência da competência linguística ou mesmo da comunicativa, qualificando-a como um tipo específico de competência requerida do tradutor/intérprete (GONÇALVES, 2005; ROTHE-NEVES, 2007; MALMKJÆR, 2009). Portanto, a competência tradutória "é claramente vista como uma expertise complexa em várias áreas: essas incluirão, pelo menos, conhecimento de línguas, conhecimento de culturas e conhecimento de domínio específico" (SCHÄFFNER, $\mathrm{ADAB}, 2000$, p. 9, tradução minha).

Nas distintas visões de alguns dos muitos autores dos Estudos da Tradução, a competência tradutória ou a competência do tradutor, de maneira geral, pode ser entendida como

[...] os conhecimentos e habilidades necessários ao tradutor para que seja capaz de traduzir. (BELL, 1991, p. 76, tradução minha).

[...] todos aqueles conhecimentos, habilidades e estratégias que o tradutor bem-sucedido possui e que conduzem a um exercício adequado da tarefa tradutória. (ALVES, MAGALHÃES, PAGANO, 2000, p. 13). 
[...] a macrocompetência que constitui o conjunto de capacidades, habilidades, conhecimentos e também atitudes que os tradutores profissionais possuem e que intervêm na tradução como atividade especializada, a qual se desmembra em subcompetências [...], todas necessárias ao êxito da macrocompetência. (KELLY, 2002, p. 14, tradução minha).

[...] a habilidade para gerar uma sequência com mais de um texto alvo viável $\left(\mathrm{TA}_{1^{\prime}} \mathrm{TA}_{2} \mathrm{TA}_{\mathrm{n}}\right)$ para um texto fonte pertinente (TF); a habilidade para selecionar apenas um TA viável dessa sequência, rapidamente e com confiança justificada. (PYM, 2003, p. 489, tradução minha).

[...] um conhecimento especializado, integrado por um conjunto de conhecimentos e habilidades, que singulariza o tradutor e o diferencia de outros falantes bilíngues não tradutores [...] que consiste em um sistema subjacente de conhecimentos declarativos e, em maior proporção, operacionais, necessários para saber traduzir [...]. (HURTADO ALBIR, 2005 , p. 19, 28).

[...] capacidades, habilidades e conhecimentos de diferentes domínios, apresentando interfaces múltiplas entre linguagem, competência textual, conhecimentos técnicos, conhecimentos culturais, capacidades motoras etc.. (GONÇALVES, 2005, p. 66).

[...] habilidades de tradução expressas por meio da capacidade crescente do tradutor em dar conta de malabarismos com as três formas de suas línguas para produzir os tipos de tradução que as normas contemporâneas requerem - ou, é claro, transgredindo as normas, se esse é o seu desejo. (MALMKJÆR, 2009, p.132, tradução minha).

Embora encontremos definições elaboradas de competência tradutória na literatura especializada dos Estudos da Tradução, muitos são os autores que adotam o termo sem explicitar o que de fato entendem como competência. A despeito disso, podemos defender, com base em diferentes abordagens da competência tradutória, que ela não é: (i) uma habilidade inata ou uma aptidão natural; (ii) a junção de competências linguísticas e/ou comunicativas; (iii) o simples agrupamento de conhecimentos, habilidades e atitudes; muito menos (iv) o mero treinamento técnico para o exercício de uma atividade profissional.

Enfim, é preciso entender que a competência tradutória é algo bem complexo que envolve aspectos cognitivos, afetivos, psicomotores e sociointerativos e que, portanto, as diferentes propostas de conceituação e os distintos modelos são uma tentativa de abordar de forma sistemática toda essa complexidade. E, muitas vezes, desenvolver aplicações didáticas à formação do tradutor e/ou intérprete, já que, em qualquer ambiente profissional, o desempenho é considerado conforme necessidades e objetivos bem definidos, o que exige um tipo específico de competência (SCHÄFFNER; ADAB, 2000).

Considerando os conceitos de competência e seu uso no campo dos Estudos da Tradução, podemos observar que não há um único posicionamento sobre o que de fato constituiria a competência tradutória, visto que sua complexidade exige um significativo esforço de conceituação, assim como de identificação e descrição de 
seus componentes, de seu funcionamento e de sua aquisição. Entretanto, muitos dos estudos sobre a competência tradutória não partem de pesquisas empíricas e, portanto, vários dos modelos propostos não possuem evidências científicas que os sustentem, assim como observam Rothe-Neves (2007), Alves (2015) e Hurtado Albir $(2005,2017)$.

Reconhecendo a magnitude do desafio de esquadrinhar a competência tradutória e a possível limitação dos modelos, assumimos, neste texto, que, assim como os demais tipos de competência profissional, a competência tradutória é um saber-agir especializado e complexo que integra de forma efetiva conhecimentos, capacidades, habilidades, atitudes e valores. E, por sua vez, compreende a mobilização e aplicação adequada, por parte do tradutor/intérprete, de recursos internos (cognitivos, afetivos, sociais, motores) e externos (físicos, tecnológicos, humanos, temporais) às tarefas específicas de tradução que demandam solução de problemas e tomadas de decisão por meio de um desempenho profissional contextualizado, intencional, situado e satisfatório.

Para refletirmos um pouco mais sobre a competência tradutória, selecionamos algumas propostas de modelos componenciais, conhecidas e difundidas entre a comunidade acadêmica dos Estudos da Tradução (i.e. BELL, 1991; HATIM; MASON, 1997; NEUBERT, 2000; KELLY, 2002; PACTE, 2003; GONÇALVES, 2005; ALVES, GONÇALVES, 2007). Como bem explica Hurtado Albir,

as décadas de 1980 e 1990 também testemunharam as primeiras propostas de modelos para CT [competência tradutória]; a maioria deles eram modelos componenciais que se concentravam na descrição dos componentes que constituem a CT. Não foram estudos específicos nem abrangentes sobre CT, no entanto, [...] eles representam as primeiras reflexões sobre o funcionamento característico da CT e seus componentes, incluindo habilidades extralinguísticas. Além disso, muitos deles surgem do interesse em desenho curricular (2017, p. 19, tradução minha).

É importante entender que esses modelos, majoritariamente propostos no contexto europeu, baseiam-se em perspectivas teóricas distintas e expressam uma tentativa de mapear o que constituiria o complexo fenômeno do traduzir, em termos do que seria necessário ao tradutor/intérprete saber (knowing what or knowing that) e saber-fazer (knowing how), por exemplo, para realizá-lo de forma adequada e bem-sucedida. Além disso, devemos salientar que existem outras reflexões relevantes sobre a competência tradutória que não abordaremos neste texto, as quais também podem contribuir significativamente com a problematização da noção de competência e com uma melhor compreensão do caráter, da constituição, do funcionamento e da aquisição desse tipo ímpar de competência. 


\subsection{0 modelo de Bell (1991) para a especificação do que seria a competência do tradutor: o que é que os tradutores devem saber e serem capazes de fazer para traduzir?}

$\mathrm{Na}$ perspectiva de Roger Bell (1991), a competência do tradutor, como comunicador, resultaria da junção de um conjunto de elementos, mais especificamente, de cinco tipos distintos de conhecimento: (i) conhecimento da língua fonte; (ii) conhecimento da língua-alvo; (iii) conhecimento do tipo de texto; (iv) conhecimento de do mínio, de área ("do mundo real"); e (v) conhecimento contrastivo, somados às habilidades de codificação (de escrita de textos alvo) e de decodificação (leitura de textos fonte).

Assim, de forma geral, o possível modelo pensado por Bell estrutura-se na integração de: (a) uma base de conhecimentos (que envolve os cinco tipos de conhecimento citados acima) e (b) um mecanismo inferencial (que diz respeito às habilidades de leitura e escrita de textos). Essa integração manifesta-se, portanto, assim como os componentes da "competência comunicativa", por meio do seguinte:

(1) competência gramatical (habilidades e conhecimentos necessários para compreender e expressar o significado literal dos enunciados);

(2) competência sociolinguística (conhecimento e capacidade de produzir e compreender enunciados contextualizados);

(3) competência discursiva (capacidade de combinar forma e significado para chegar a textos em diferentes gêneros) ${ }_{i} \mathrm{e}$

(4) competência estratégica (empregada para melhorar a eficácia da comunicação e compensar possíveis deficiências), com destaque para esta última.

Dito de outro modo, na visão de Bell, a competência do tradutor demanda competência linguística nas línguas de trabalho e competência comunicativa nas culturas que envolvem essas línguas, ou seja, depende diretamente dos "conhecimentos e capacidades que o tradutor possui e que lhe permitem criar atos comunicativos - discurso - que não são apenas (e não necessariamente) gramaticais, mas... socialmente apropriados". (BELL, 1991, p. 42, tradução minha).

\subsection{A análise de Hatim e Mason (1997) sobre atos de tradução como atos de comunicação: como chegar a uma taxonomia viável de habilidades do tradutor para avaliar seu desempenho?}

Para definir as capacidades requeridas dos tradutores, Basil Hatim e Ian Mason (1997) baseiam-se na análise da habilidade comunicativa de linguagem, realizada por Bachman (1990), a qual considera três categorias de conhecimentos 
e habilidades relacionadas à competência linguística, a saber: (i) competência organizacional (incluindo competência gramatical e textual); (ii) competência pragmática (incluindo competência ilocucionária e sociolinguística); e (iii) competência estratégica (que atua na avaliação da relevância, eficiência e eficácia com funções de averiguação, planejamento e execução na definição de meios mais adequados ao alcance de um dado propósito comunicativo).

Eles oferecem um modelo de competência composto por um processo de três etapas:

(1) processamento do texto fonte;

(2) transferência; e

(3) processamento do texto alvo.

A partir disso, apresentam um quadro onde elencam uma serie de habilidades requeridas do tradutor em cada uma dessas etapas, as quais são complementares e interagem no decorrer da atividade tradutória, algumas vezes se sobrepondo. Segundo eles, "a divisão em um processo de três estágios é, até certo ponto, artificial, dado que essas atividades são pelo menos parcialmente concomitantes". (HATIM; MASON, 1997, p. 205, tradução minha).

Durante o processamento do texto fonte, conduzido em termos do efeito estimado sobre o seu leitor, são necessárias habilidades para: reconhecer a intertextualidade (gênero, discurso, texto); identificar a situacionalidade (registro, etc.); inferir a intencionalidade; organizar a textura (escolhas lexicais, organização sintática, coesão) e a estrutura textual; e avaliar a informatividade (se são textos estáticos ou dinâmicos).

$\mathrm{Na}$ etapa de transferência, com base em suas habilidades, o tradutor estabelece uma renegociação estratégica, realizando ajustes em relação à eficiência (menos esforço do leitor), eficácia (alcance do objetivo comunicativo) e relevância (contexto, objetivo e destinatário específicos) com a finalidade de projetar para seu público, conforme suas necessidades, os objetivos comunicativos do texto, cumprindo assim com um dado propósito retórico.

Por fim, na fase de processamento do texto alvo, administrada em termos do efeito estimado sobre o seu leitor, o destinatário da tradução, são demandadas habilidades comparáveis às da fase de processamento do texto fonte, ainda que operem de maneira um pouco distinta. Temos o seguinte: estabelecer a intertextualidade (gênero, discurso, texto); elaborar a situacionalidade (registro, etc.); produzir a intencionalidade; organizar a textura (escolhas lexicais, organização 
sintática, coesão) e a estrutura textual, e equilibrar a informatividade (textos mais ou menos estáticos ou dinâmicos).

É importante mencionar que, embora proponham esse modelo didaticamente organizado em três etapas, Hatim e Mason (1997) reconhecem a integração entre essas etapas, já que as decisões tomadas em qualquer uma delas afetam necessariamente a(s) outra(s).

\subsection{A reflexão de Neubert (2000) sobre a complexidade da competência tradutória e a inter-relação eficiente, efetiva e adequada entre competências: como dar conta das infinitas áreas e inumeráveis processos que surgem de maneiras sempre novas no trabalho do tradutorlintérprete?}

Destacando a singularidade da atividade do tradutor, Albrecht Neubert (2000) apresenta sete características da competência tradutória, as quais estão intrinsicamente ligadas, a saber: (i) complexidade; (ii) heterogeneidade; (iii) aproximação; (iv) abertura (open-endedness); (v) criatividade; (vi) situacionalidade e (vii) historicidade. Por sua vez, são mencionadas as características inerentes à tradução e ressaltados os aspectos profissionais que envolvem a atividade tradutória, no intuito de deixar claro que a competência tradutória requer muito mais que conhecimento linguístico e que, além disso, não se resume à capacidade de transferência entre línguas.

Com base nessa caracterização da competência tradutória, Neubert estabelece a distinção entre componentes primários (substanciais) e secundários (contextuais) desse tipo de competência, sendo que os secundários referem-se às características citadas acima. E, a partir disso, apresenta cinco parâmetros por meio dos quais os tradutores desenvolvem sua competência:

(1) competência linguística (conhecimento dos sistemas gramaticais e lexicais das línguas de trabalho, incluindo repertórios linguísticos para fins específicos);

(2) competência textual (domínio dos elementos, sistemas textuais e discursivos, diferentes tipos e gêneros textuais);

(3) competência temática (conhecimentos enciclopédicos e específicos);

(4) competência cultural (conhecimento dos padrões culturais e de seus contrastes); $\mathrm{e}$

(5) competência de transferência (conhecer as táticas e estratégias de conversão de textos de uma língua à outra e saber aplicá-las, capacidade de combinar as demais competências). 
Segundo Neubert (2000), é exatamente a inter-relação entre esses distintos tipos de competências que distingue a tradução de outras atividades comunicativas, sendo que a competência de transferência "domina sobre todas as demais competências, ou seja, as habilidades de transferência integram os conhecimentos linguístico, textual, temático e cultural com o único objetivo de satisfazer as necessidades de transferência". (NEUBERT, 2000, p. 6, tradução minha).

\subsection{A busca de Kelly (2002) por um modelo que possa servir de base para o desenho curricular: como construir um modelo da competência tradutória e seus componentes que seja o mais completo possível?}

Considerando algumas descrições e modelos existentes de competência tradutória, bem como uma perspectiva que denomina como profissional, proposta pelo Language Professionals Lead Body do Reino Unido, Dorothy Kelly (2002) apresenta um modelo de competência que "pretende servir de base para o desenho curricular e para o planejamento de conteúdos e de metodologia no âmbito da formação universitária de tradutores". (p.14, tradução minha).

Em relação ao modelo de competência tradutória proposto, Kelly (2002), da Universidade de Granada, Espanha, explica que: (i) as subcompetências que o compõem não são uma exclusividade de tradutores e que, portanto, seria sua combinação em conjunto e inter-relação que distinguiria a competência tradutória de outras atividades especializadas; (ii) as subcompetências não intervêm da mesma forma em toda a diversidade de atividades tradutórias, podendo agir em menor ou maior grau; (iii) existem fatores individuais e particulares que interferem no rendimento de cada tradutor, já que estes se desenvolvem em diferentes graus, de acordo com o estágio em que se encontram profissionalmente; e (iv) suas referências à tradução profissional ou experta dizem respeito às atuações exitosas que satisfaçam critérios de qualidade.

Seu modelo é constituído por sete distintos componentes, nomeados por ela como subcompetências:

(1) subcompetência comunicativa e textual (engloba conhecimentos e habilidades de comunicação, assim como domínio das convenções textuais);

(2) subcompetência cultural (refere-se ao conhecimento enciclopédico e, também, aos valores, aos mitos, às percepções, às crenças e aos comportamentos e suas representações textuais);

(3) subcompetência temática (compreende os conhecimentos elementares dos campos temáticos em que o tradutor atua); 
(4) subcompetência instrumental profissional (diz respeito à manipulação de recursos e de ferramentas de apoio à tradução e também à gestão da prática profissional);

(5) subcompetência psicofisiológica (abarca a consciência do que é ser tradutor, bem como outras capacidades, tais como confiança, atenção, memória, etc.);

(6) subcompetência interpessoal (envolve a capacidade de relacionar-se com os outros e a de trabalhar em equipe); e

(7) subcompetência estratégica (abrange os procedimentos referentes à organização e realização do trabalho, à identificação e resolução de problemas, à autoavaliação e à revisão).

Kelly (2002) esclarece que todas as subcompetências são inter-relacionadas e que a subcompetência estratégica é a responsável em conduzir a aplicação de todas as demais competências durante a realização de uma tarefa específica de tradução. Considerando essa centralidade da subcompetência estratégica, vista como "competência de transferência", ela apresenta uma estruturação piramidal de base hexagonal da competência tradutória, na qual essa subcompetência ocupa o ápice.

\subsection{A pesquisa empírico-experimental do Grupo PACTE (2001, 2003; HURTADO ALBIR, 2017) e seu modelo holístico e dinâmico da competência tradutória: o que constitui a competência tradutória e como se dá sua modelagem, aquisição, funcionamento e desenvolvimento?}

O modelo final de competência tradutória do Grupo PACTE - Procés d'Adquisició de la Competència Traductora i Avaluació (2003; HURTADO ALBIR, 2017) da Universidade Autônoma de Barcelona, Espanha, resulta do aperfeiçoamento de seu primeiro modelo (PACTE, 2001). Ao realizarmos uma comparação entre a primeira e a última versão do modelo proposto, observamos que houve uma alteração de qualidade, função e denominação dos componentes da competência tradutória, bem como de sua relação e hierarquia.

O primeiro modelo integrava seis competências inter-relacionadas (comunicativa em duas línguas, extralinguística, psicofisiológica, instrumental/ profissional, de transferência e estratégica), com destaque para a competência estratégica e sua função de regular e compensar as possíveis deficiências das demais subcompetências e, hierarquicamente, para a competência de transferência responsável em integrar as demais subcompetências (PACTE, 2001). Em relação à representação do modelo, é importante dizer que em seu centro estava a competência de transferência, rodeada pelas demais competências, tudo interligado, com exceção 
da competência estratégica que estava situada em um espaço distinto das demais competências centrais, ou seja, fora do centro do modelo, ainda que ligada a ele.

O atual modelo do Grupo PACTE (2003; HURTADO ALBIR, 2017), embora alterado, mantém uma proposta de integração, distinção e hierarquia entre as subcompetências que constituem a competência tradutória. Assim, temos o seguinte:

(1) subcompetência bilíngue (composta por conhecimentos essencialmente operacionais, importantes à comunicação em duas línguas);

(2) subcompetência extralinguística (formada por conhecimentos, essencialmente declarativos, acerca do mundo e de esferas particulares);

(3) subcompetência de conhecimentos sobre a tradução (constituída por conhecimentos, essencialmente declarativos, sobre a tradução, os princípios que a regem e seus aspectos profissionais);

(4) subcompetência instrumental (integrada por conhecimentos, essencialmente operacionais, referentes ao uso de fontes de documentação e de tecnologias de informática e comunicação aplicadas à tradução);

(5) subcompetência estratégica (consiste em conhecimentos operacionais para garantir a eficácia do processo tradutório e possui um caráter central no controle desse processo); e

(6) componentes psicofisiológicos (componentes cognitivos, aspectos de atitude, habilidades etc.).

No modelo atual, a competência estratégica passa a ocupar o lugar que antes ocupava a competência de transferência, ou seja, por controlar todo o processo tradutório, por afetar diretamente todas as demais subcompetências e por ser capaz de reparar possíveis deficiências, ela é deslocada para o centro do modelo. A competência comunicativa passa a ser chamada de competência bilíngue. É apresentada uma competência específica de conhecimentos sobre a tradução, como resultado de um desmembramento da competência instrumental/ profissional do modelo anterior. A competência psicofisiológica deixa de ser vista como uma subcompetência e passa a ser considerada apenas como componentes psicofisiológicos, assumindo o lugar antes dado à competência estratégica, fora do centro do modelo.

Por fim, é importante destacar que na modelagem da competência tradutória proposta pelo Grupo PACTE, entende-se que a interação entre as subcompetências é variável, visto que depende de diversos elementos, tais como a direção da tradução (direta ou inversa), a combinação linguística, o tipo de tradução, o nível 
de experiência do profissional, o contexto situacional no qual o processo se realiza, dentre outros.

\subsection{A indagação de Gonçalves (2005) sobre os parâmetros cognitivos para mensuração da competência do tradutor: haveria uma competência tradutória geral que se apresenta como uma interface de várias competências, conhecimentos, habilidades e estratégias e outra específica que distingue o tradutor do bilíngue?}

Baseado no modelo de competência tradutória do grupo PACTE (2003), assim como em outros autores que têm investigado e discutido a constituição da competência tradutória, em abordagens conexionistas (ELMANN et al., 1996) e numa perspectiva relevantista (GUTT, 2000; ALVES, 1996; SPERBER; WILSON, 1995), José Luiz Gonçalves (2005), da Universidade Federal de Ouro Preto, Brasil, tece uma reflexão sobre a natureza predominante da competência tradutória, problematizando, por sua vez, a relação do conhecimento declarativo com o procedimental e do processamento automático com o processamento metacognitivo. Para o autor, a competência tradutória inclui uma serie de processos cognitivos, biológicos e sociointerativos, muitos dos quais não são exclusivos à tarefa tradutória.

A partir disso, Gonçalves $(2005$, p. 62) propõe uma diferenciação entre uma competência tradutória geral e uma competência tradutória específica, a qual possui componentes singulares que "tornam o tradutor competente mais apto a traduzir que o falante bilíngue/bicultural". Essa competência tradutória específica

caracteriza-se pela maximização dos efeitos contextuais gerados pelo processamento de unidades de tradução recíprocas, uma na língua-fonte e outra na língua-alvo, e também pela maximização da superposição entre esses efeitos contextuais, ou seja, pela maximização da sua semelhança interpretativa. (GONÇALVES, 2005, p. 62).

O modelo proposto por Gonçalves (2005, p.70) estrutura-se a partir de "diversos níveis de processamento cognitivo e sua relação com os diferentes aspectos no entorno da cognição", os quais se organizam num processo de complexificação, com acréscimo dos componentes da competência tradutória geral (KAT - subcompetência de conhecimentos sobre tradução; INST - subcompetência profissional/instrumental, $\mathrm{PP}$ - componentes psicofisiológicos, $\mathrm{CTe}$ - competência tradutória específica que é uma competência pragmática interlingual), "dentre os 
quais se destaca a CTe [competência tradutória específica] como subcomponente fundamental da competência do tradutor". Vejamos o modelo.

TA- Texto Alvo

TF- Texto Fonte

LA- Língua Alvo

LF- Língua Fonte

UT- Unidade de Tradução

(1) INST - Subcompetência Profissional/Instrumental

(2) KAT- Subcompetência de Conhecimentos sobre Tradução

(3) PP-Componentes Psicofisiológicos

(4) CTe-Competência Tradutória Específica

1. Meta-cognição/ Meta-representações

2. Atitudes Proposicionais, Subjetividade

3. Conhecimento Declarativo

4. Conhecimento Procedimental

5. Percepção/Produção, Nível Sensório-motor

6. Nível Comportamental

7. Sociointeração

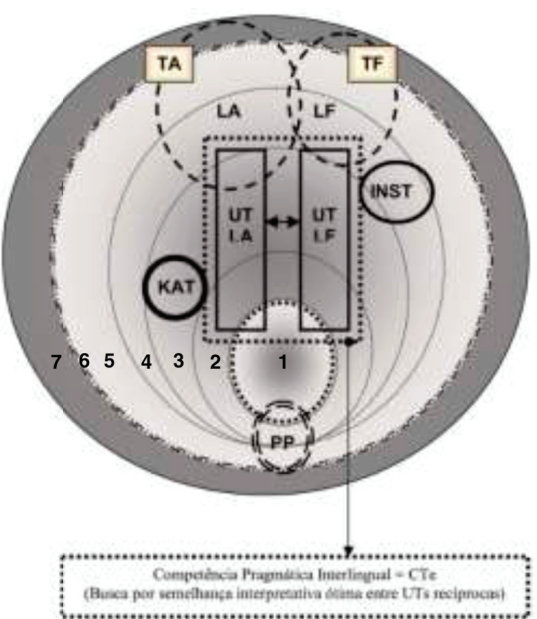

Figura 1. Situando os componentes da Competência Tradutória: o modelo de Gonçalves (2005) Fonte: Gonçalves, 2005, p. 77 (adaptado)

O modelo proposto por Gonçalves (2005) demanda uma leitura minuciosa de sua representação, já que cada detalhe foi pensado no intuito de ilustrar diferentes aspectos cognitivos, biológicos e sociointerativos da competência do tradutor. Vale mencionar, assim como destaca Alves (2015, p.301), que a representação do modelo "indica que um determinado estímulo cognitivo pode repercutir no processo de tradução tanto de forma procedimental quanto de maneira declarativa".

Gonçalves contribui com a compreensão da complexidade da atividade tradutor em sua busca por semelhança interpretativa ótima. Segundo ele, "o conceito de semelhança interpretativa destaca um tipo de processo linguístico pragmático especializado, que poderia representar o principal diferencial entre o tradutor competente e o bilíngue" $(2005$, p.85). É nessa direção que o autor apresenta sua proposta de competência do tradutor, a qual está bem afinada às ciências cognitivas, inaugurando assim uma perspectiva reflexiva diferente da apresentada pelos modelos citados anteriormente (BELL, 1991; HATIM; MASON, 1997; NEUBERT, 2000; KELLY, 2002; PACTE, 2003) e, por sua vez, mais plausível em termos biológicos. 


\subsection{A proposta de Alves e Gonçalves (2007) para a ampliação do espectro e alcance do modelo de competência do tradutor de Gonçalves (2005): teríamos diferentes perfis tradutórios: tradutores com espectro reduzido (narrow-band translator) e tradutores com espectro amplo (broadband translator)?}

O modelo de Fábio Alves ${ }^{1}$ e José Luiz Gonçalves (2007) é um aperfeiçoamento do modelo de Gonçalves (2005), apresentado acima (Figura 1). A proposta dos autores foi realizar um refinamento desse modelo cognitivo e dinâmico a partir da lógica que o sustenta e da avaliação de sua plausibilidade, o que é feito em termos da definição de diferentes perfis tradutórios. Com base em estudos empíricos anteriores (i.e. GONÇALVES, 2003; ALVES; GONÇALVES, 2003; ALVES, MAGALHÃES, 2004; ALVES, 2005a, 2005b), os autores estabelecem uma distinção entre (i) tradutor com espectro reduzido/ banda-restrita (narrow-band translator) e (ii) tradutor com espectro amplo/ banda-larga (broadband translator).

Nesse sentido, temos que um tradutor com espectro reduzidoé aquele que atua, sobretudo, no nível lexical. E, portanto, trabalha, predominantemente, com base em pistas comunicativas insuficientemente contextualizadas (significado dicionarizado ao invés de contextualizado) e tem dificuldade em tratar coordenadamente a informação codificada conceitual, procedimental e contextualmente. Dito de outro modo, existe um baixo desenvolvimento das subcompetências, pouca integração entre elas e, especialmente, uma pequena amplitude da competência específica, "a qual se restringe aos níveis da equivalência/correspondência linguística entre unidades de tradução, não chegando a níveis adequados de contextualização [...]". (GONÇALVES, 2008, p. 130).

Por outro lado, o tradutor de espectro amplo é aquele que atua, sobretudo, fundamentado em pistas comunicativas reforçadas pelas suposições contextuais derivadas de seu ambiente cognitivo. Assim, são capazes de integrar a informação codificada conceitual, procedimental e contextualmente de forma completa e coerente. Como destaca Alves $(2015$, p.304),

o tradutor com espectro amplo tem a capacidade de processar em paralelo os significados codificados conceitual e procedimentalmente. Desta forma, consegue enriquecer inferencialmente os enunciados codificados no texto-fonte com informações de cunho contextual e atribuir a eles um alto nível de semelhança interpretativa com a contrapartida textual instanciada no texto-alvo.

1. Universidade Federal de Minas Gerais, Brasil. 
Esse dois perfis resultam em modificações no modelo de Gonçalves (2005), do qual derivam dois vieses do modelo original, os quais passam a orientar-se pelo perfil do tradutor: o espectro amplo e o espectro reduzido, citados acima. No que se refere à representação dos modelos, temos que:

(1) Espectro reduzido: o espaço onde se localizam a língua fonte (LF), a língua alvo (LA), a subcompetência Profissional/Instrumental (INST), a subcompetência de Conhecimentos sobre Tradução (KAT) e os Componentes Psicofisiológicos (PP) está circunscrito à parte mais superior do modelo, significativamente afastada de seu centro, e, por sua vez, fora do alcance da atividade meta-cognitiva do tradutor. Nesse sentido, a competência tradutória específica (CTe) encontra-se limitada, em relação ao modelo de Gonçalves (2005), apresentado acima (figura 1).

(2) Espectro amplo: o espaço onde se localizam a língua fonte (LF), a língua alvo (LA), a subcompetência Profissional/Instrumental (INST), a subcompetência de Conhecimentos sobre Tradução (KAT) e os Componentes Psicofisiológicos (PP) é bem similar àquele que possuem no modelo original de Gonçalves (2005), já que se aproximam do centro do modelo e, portanto, compreendem a atividade cognitiva do tradutor (vide a figura 1). Há, entretanto, um destaque para a relação entre as unidades de tradução da língua fonte e da língua alvo, a qual evidencia "a capacidade de graduar apropriadamente a semelhança interpretativa, da semelhança microlinguística à meta-contextual". (ALVES; GONÇALVES, 2007, p. 52, tradução minha).

Por fim, o aperfeiçoamento proposto por Alves e Gonçalves (2007), evidencia que, embora tradutores de distintos perfis, espectro reduzido ("novato") e espectro amplo ("experto"), compartilhem uma serie de características, tais características possuem distintos níveis de evolução, o que sugere que a competência do tradutor consiste de

[...] um conjunto de comportamentos cognitivos agrupados ao longo de um continuum que se estende da mera transferência de itens codificados linguisticamente até o ponto em que o tradutor integra completamente um conjunto mais complexo de subcompetências e se dispõe a assumir conscientemente a responsabilidade por suas decisões. (ALVES, GONÇALVES, 2007 , p. 53, tradução minha).

A aproximação a estas distintas propostas de modelagem da competência tradutória ou de competência do tradutor possibilita que observemos pontos comuns, assim como algumas disparidades entre os modelos. De qualquer maneira, podemos nos certificar de que a definição, a descrição e a modelagem da competência é uma atividade complexa e desafiadora. 


\section{A MODALIDADE DE LÍNGUA E A COMPETÊNCIA DO TRADUTOR/INTÉRPRETE DE LÍNGUA DE SINAIS}

Ao abordar a competência tradutória, Neubert (2000), assim como outros teóricos, chama atenção para a sua complexidade, heterogeneidade e singularidade, destacando que diversos aspectos contextuais marcam todos os processos tradutórios. Tais aspectos interferem na maneira por meio da qual os componentes da competência tradutória se inter-relacionam e, por sua vez, funcionam diante de um dado encargo de tradução. Segundo ele, uma questão que se apresenta é a diversificação da competência tradutória, já que esta varia de acordo com o perfil profissional requerido do tradutor, o assunto a ser traduzido e a direcionalidade da tradução, por exemplo.

Reconhecendo essa complexidade inerente à competência tradutória, assim como à sua aquisição e ao seu funcionamento, o Grupo PACTE (HURTADO ALBIR, 2017) afirma que a interação entre as subcompetências é variável segundo: (i) a direcionalidade (direta - B para A, ou inversa - A para B); (ii) a combinação linguística (línguas mais próximas e mais distantes, etc.); (iii) a especialidade (técnica, literária, jurídica etc.); (iv) a modalidade (escrita, à prima vista, legendagem, simultânea etc.); (v) o grau de experiência do tradutor; (vi) o contexto situacional, dentre outros. Nesse sentido, torna-se possível refletir sobre as diversas variáveis capazes de interferir na competência requerida para a realização de uma determinada tradução/interpretação.

Seguindo essa lógica - ainda que nenhum dos modelos de competência tradutória faça referência direta às línguas de modalidade gestual-visual ou aos tradutores e intérpretes de línguas de sinais - pode-se dizer que a competência tradutória seria afetada, inclusive, pela modalidade das línguas envolvidas no processo de tradução. Assumindo essa possibilidade, cabe mencionar a necessidade de reflexões capazes de iluminar as maneiras por meio das quais a modalidade de língua: (i) poderia ser relacionada aos diferentes componentes da competência tradutória; (ii) seria capaz de interferir na interação que há entre eles; e, inclusive, (iii) poderia influenciar na maneira de compreendê-los e de defini-los. Dito de outro modo, a competência requerida dos tradutores e intérpretes que atuam entre duas línguas vocais-auditivas (escritas ou faladas) é similar àquela requerida dos tradutores e intérpretes de línguas de sinais, que atuam entre uma língua vocal auditiva (escrita ou falada) e outra gestual-visual (escrita ou sinalizada)?

Podemos tentar responder a esta questão por diferentes caminhos. Entretanto, considerando a complexidade da competência tradutória e a necessidade de pesquisas empíricas sobre ela, optamos apenas por propor um olhar inicial sobre 
as possíveis questões que a modalidade de língua pode trazer à compreensão, à descrição, ao funcionamento e à modelagem desse tipo específico de competência.

\subsection{Características das línguas de modalidade gestual-visual}

Um ponto central à nossa reflexão, para além da definição e compreensão da competência tradutória, é o entendimento do que queremos dizer com o termo modalidade quando nos referimos à língua. Para tanto, nos valeremos da explicação apresentada por McBurney, que nos diz que "[...] a modalidade de uma língua pode ser definida como sendo os sistemas físicos ou biológicos de transmissão por meio dos quais sua fonética se realiza" (2004, p. 351, tradução minha).

Com base nessa definição de modalidade, temos que considerar, portanto, a possibilidade de existência de diferentes sistemas de produção e percepção de línguas. Assim, podemos afirmar que as línguas orais, de modalidade vocal-auditiva (oral-auditiva), contam com um sistema de articulação vocal e um sistema auditivo de recepção, contrastando-se às línguas de sinais, de modalidade gestual-visual (manualvisual, espaço-visual), que contam com um sistema gestual de produção e um visual para sua percepção (STOKOE, 1960; KLIMA; BELLUGI, 1979; BRITO, 1995; MEIER $;$ COMIER; QUINTO-POZOS, 2004; COSTELLO, 2015, etc.).

Fica claro, então, que a capacidade humana para linguagem manifesta-se por, pelo menos, duas modalidades de língua e que isso já pressupõe uma diferença de interface articulatório-perceptual entre línguas orais e de sinais (MEIER, 2004; MEIER $_{i}$ COMIER; QUINTO-POZOS, 2004; QUADROS, 2006). Desse fator fundamental decorre um conjunto de diferenças entre essas duas modalidades, visto que, enquanto as línguas orais têm articuladores relativamente pequenos e internos ao corpo que manipulam sinais acústicos, os quais necessitam de recepção auditiva; línguas de sinais contam com articuladores comparativamente maiores, simétricos, externos ao corpo e visíveis, que criam sinais gestuais dependentes de sua recepção visual.

Os estudos linguísticos têm demonstrado tanto o que há em comum entre as línguas orais e as de sinais, evidenciando que existem propriedades linguísticas que não estão restritas à modalidade de língua, quanto apresentado características específicas das línguas de sinais, as quais se vinculam aos efeitos da modalidade e podem ser vistas como dispositivos linguísticos específicos (KLIMA; BELLUGI, 1979). De maneira sucinta, podemos dizer que esses efeitos, diretamente relacionados às características fonéticas da língua, dizem respeito ao fato de a língua se constituir por meio dos movimentos do corpo no espaço, sem nenhuma dependência de 
sinais acústicos. De acordo com Rodrigues (2013a), a modalidade vocal-auditiva e a gestual-visual

\footnotetext{
distinguem-se no que tange ao seu modo de produção e recepção, o que traz algumas implicações tais como o fato de as línguas de sinais serem bem mais simultâneas que as orais, mais sintéticas e possuírem dispositivos linguísticos específicos (expressões faciais gramaticais, classificadores, possibilidade de os sinais incorporarem informações etc.). (p. 114, grifos do autor).
}

Em suma, as propriedades gestuais, espaciais e visuais que caracterizam as línguas de sinais interferem em sua estruturação fonológica e morfológica (marcadamente gestual), em sua organização sintática (acima de tudo espacial), em seu sistema pronominal e em sua concordância verbal (STOKOE, 1960; KLIMA; BELLUGI, 1979; BRITO, 1995; MEIER; COMIER; QUINTO-POZOS, 2004; HOHENBERGER; HAPP; LEUNINGER, 2004; QUADROS, KARNOPP, 2004, etc.).

Por fim, ao trazer à tona outra possibilidade de produção e percepção da língua com seus efeitos e não efeitos, esses estudos têm contribuído com a linguística e suas áreas afins, inclusive com os Estudos da Tradução e os da Interpretação.

\subsection{Singularidades da atuação tradutória e interpretativa intermodal}

No campo dos Estudos da Tradução e da Interpretação de Línguas de Sinais, pesquisas empíricas têm demonstrado que a modalidade de língua traz certas implicações para o processo tradutório e interpretativo (PADDEN, 2000; WURM, 2010; SOUZA, 2010; RODRIGUES, 2012, 2013a, 2013b, 2013c; SILVÉRIO et al., 2012; SEGALA; QUADROS, 2015; LOURENÇO, 2015; RODRIGUES; MEDEIROS, 2016; NOGUEIRA, 2016, dentre outros). Embora não seja nosso enfoque primordial nesse texto, vale mencionar que, não somente a modalidade de língua tem efeitos sobre a tradução e a interpretação de/para línguas de sinais, já que outros aspectos sociais e históricos envolvendo as línguas de sinais e as comunidades surdas, minoria linguística e cultural, também marcam esses processos interlinguísticos e interculturais.

Os intérpretes e os tradutores de línguas de sinais têm sido responsáveis por um duplo movimento que, se por um lado, possibilita que informações e conhecimentos cheguem às comunidades surdas, por outro, transporta os saberes produzidos por essas comunidades da margem ao centro do debate atual. Esse movimento se dá, por exemplo, por meio de traduções que partem das línguas de sinais tendo como fim as diversas línguas orais, inclusive em sua modalidade escrita. De acordo com Rodrigues e Quadros (2015, p. 82), temos atualmente no Brasil, 
assim como na América Latina, "[...] a difusão de certa consciência multilíngue nos processos de tradução e de interpretação da/para a Libras, na visibilização de diferenças e linguagens surdas e na negociação linguística e cultural entre surdos e ouvintes."

É importante destacar que "os surdos e a surdez, sujeitos e temática, ignorados por séculos, hoje constituem e expressam um campo específico de saber, o qual tem sido significado e caracterizado por dimensões e aspectos culturais, antes improváveis e impensáveis" (RODRIGUES, 2011, p. 30). Nesse sentido, as comunidades surdas têm se tornado protagonistas e, inclusive, influenciado os modos de se compreender e de se pensar a tradução e a interpretação, bem como de se definir o conjunto de conhecimentos, habilidades e atitudes necessários aos tradutores e aos intérpretes de línguas de sinais.

Levar em conta a especificidade da situação vivenciada pelos surdos e a forma com que a modalidade gestual-visual caracteriza e impacta os processos tradutórios e, por sua vez, a competência dos tradutores e intérpretes, é um elemento indispensável às atuais reflexões sobre como: (i) lidar com e compreender as minorias linguísticas e culturais; (ii) pensar os processos tradutórios e interpretativos para além da transposição semiótica com foco no linguístico; e (iii) conceber e (re)significar as funções e finalidades da tradução, da transferência e da mediação linguística e cultural na (trans)formação da sociedade atual.

Portanto, cientes dos aspectos históricos, sociais e culturais que podem interferir na interpretação e na tradução de/para as línguas de sinais e considerando a modalidade de língua como um elemento diferenciador dos processos tradutórios, podemos dizer que, no que se refere ao caráter da tradução segundo a modalidade das línguas, temos: (i) tradução e interpretação intermodal (entre línguas de distintas modalidades - uma vocal-auditiva e outra gestual-visual); (ii) tradução e interpretação intramodal (entre línguas de mesma modalidade - entre duas línguas vocais-auditivas ou entre duas línguas gestuais-visuais). A partir dessa diferenciação, destacamos que, neste texto, não estamos levando em conta as especificidades dos processos tradutórios e/ou interpretativos intramodais gestuais-visuais, ou seja, aqueles que ocorrem entre duas línguas de sinais.

Dentre os vários efeitos que a modalidade de língua pode ter sobre os processos tradutórios ${ }^{2}$ e/ou interpretativos intermodais, destacamos dois deles para

2. A tradução de línguas de sinais pode envolver a escrita, ainda que não tenhamos um sistema consolidado de escrita de sinais com pleno reconhecimento e circulação social. Por esse e outros fatores, tem sido mais comum a tradução para a língua de sinais envolvendo o registro em vídeo do corpo do tradutor como língua. 
fundamentar e conduzir nossa reflexão sobre uma possível competência tradutória, propriamente intermodal, a saber: (i) a performance corporal-visual requerida do tradutor/ intérprete durante à realização da tradução/interpretação para língua de sinais; e (ii) a possibilidade da sobreposição de línguas durante o processo tradutório/interpretativo intermodal (code-blending).

No que tange à performance corporal-visual, temos a indissociabilidade do tradutor e/ou do intérprete de seu texto alvo, quando este está construído em língua de sinais. Isso ocorre pela necessidade de que os tradutores e os intérpretes intermodais estejam sempre visíveis diante do público, já que seu corpo em movimento é que constitui a língua de sinais, a qual possui certos dispositivos linguísticos específicos. Considerando essa singularidade das línguas de sinais, Padden afirma que "[... um intérprete hábil incorpora dimensões espaciais ao conteúdo da língua oral por ser isto mais significativo para os sinalizantes e porque há a oportunidade de usar sinais mais densamente enriquecidos durante a tradução [...]". (2000, p. 180, tradução minha).

A modalidade gestual-visual possibilita a exploração da simultaneidade e da iconicidade ${ }^{3}$, permitindo que, durante a sinalização, os tradutores e/ ou os intérpretes incorporem seus referentes e representem suas falas, atitudes, ações, pensamentos e/ou emoções (embodiment and role shift - action role shift, atitude role shift), desencadeando alterações contextuais e de perspectiva e, também, usem elementos gestuais, manuais e não manuais, para indicar tipo, tamanho e forma de objetos, por exemplo. Além disso, torna-se viável a exploração sistematizada do espaço, o que favorece a localização de referentes, a marcação da concordância e o uso de classificadores, dentre outros (STOKOE, 1960; KLIMA; BELLUGI, 1979; BRITO, 1995; MEIER; COMIER; QUINTO-POZOS, 2004; QUADROS; KARNOPP, 2004; QUER, et al., 2017, etc.).

Em relação à sobreposição de línguas, ou seja, à possibilidade de uso concomitante das duas línguas envolvidas no processo intermodal: uma vocal-auditiva (usando a fala e a audição) e outra gestual-visual (usando os sinais e a visão), observa-se a necessidade de que tradutores e intérpretes intermodais administrem quando devem ou não sobrepor línguas (QUADROS; SOUZA, 2008; METZGER; QUADROS, 2012; RODRIGUES, 2013a; RODRIGUES; MEDEIROS, 2016, dentre outros).

3. A iconicidade é aqui entendida como uma característica formal da língua. Ela diz respeito à relação estabelecida entre signo-objeto, ou seja, entre os sinais e a imagem ou realidade daquilo que representam. Os signos das línguas de sinais que são motivados por alguma qualidade ou propriedade de seu referente são considerados icônicos, já que, por compartilharem algum traço com seu referente, indicam alguma(s) de suas qualidades ou propriedades. 
Nesse sentido, eles precisam despender um controle executivo distinto, em parte, daquele requerido dos tradutores e intérpretes intramodais que não precisam empregar um esforço cognitivo extra para inibir a língua que não é alvo de sua expressão (i.e. os profissionais intramodais só podem realizar a alternância de códigos - code-switching). Portanto, os tradutores e os intérpretes intermodais precisam de habilidades específicas para lidar com a sobreposição de línguas e, por sua vez, com a possibilidade de fusão de elementos linguísticos por meio da realização de sinais durante a vocalização (tradução da língua de sinais para a oral) e, principalmente, da pronúncia de palavras durante a sinalização (tradução da língua oral para a de sinais).

De maneira geral, não levando em consideração as diferenças entre a interpretação intermodal e a tradução intermodal, propriamente dita, ou as diversas manifestações singulares dos processos intermodais segundo a especialidade, as múltiplas modalidades, os distintos contextos situacionais, dentre outros, delinearemos uma visão geral da maneira por meio da qual a questão da modalidade de língua pode acarretar uma possível competência tradutória intermodal.

\subsection{Existiria um modelo de competência tradutória intermodal?}

Um aspecto importante que certamente interfere na competência tradutória é a proximidade ou distância entre as línguas. Na comparação das línguas orais com as de sinais, vemos que há uma distância relativa que se impõe por meio da diferença de modalidade. Essa distância faz que, muitas vezes, as línguas vocais-auditivas não atuem eficazmente como facilitadoras do aprendizado e desenvolvimento das propriedades gestuais, espaciais e visuais das línguas de sinais. Com base em investigações empíricas e em relatos de profissionais tradutores e intérpretes de Libras, Lourenço afirma que

[... ] uma das dificuldades encontradas no processo de transposição da língua oral para a língua de sinais, e vice-versa, é justamente o fato de as linguas de sinais fazerem uso do espaço de sinalização e de movimentos com as mãos e com o corpo para veicular informações de maneira quadridimensional, enquanto as línguas orais fazem uso de um sistema linear de encadeamento de informações no fluxo de fala. (LOURENÇO, 2015, p. 321, grifos meus).

Considerando que os tradutores e intérpretes devem ser fluentes em língua de sinais, e, portanto, já terem bem desenvolvida sua competência bilíngue, é importante pensar sobre quais seriam os mecanismos físico-motores e cognitivos ativados quando um tradutor ou intérprete intermodal está a operar, concomitantemente, com línguas de distintas modalidades. Além disso, vale refletir sobre o seguinte: qual seria a interferência de uma língua sobre a outra e de uma 
modalidade sobre a outra durante o processo tradutório e/ou o interpretativo? E sobre: como essa influência interlinguística e intermodal afetaria o desempenho do tradutor/intérprete de língua de sinais e o seu texto alvo produzido em língua de sinais, sua segunda língua, na maioria dos casos, ou mesmo em língua oral, sua língua materna? Essas são apenas algumas das muitas questões que podem orientar futuras pesquisas e nos ajudar a pensar a possível singularidade da competência requerida do tradutor e do intérprete de língua de sinais.

Com base nos modelos componenciais apresentados acima (BELL, 1991; HATIM; MASON, 1997; NEUBERT, 2000; KELLY, 2002; PACTE, 2003), temos que todos aqueles componentes relacionados diretamente às línguas e ao seu uso (competências, conhecimentos, habilidades e/ou capacidades de cunho gramatical, textual, comunicativo, discursivo, sociolinguístico e/ou pragmático) serão, necessariamente, marcados pela modalidade gestual-visual e por seus efeitos, já que, como vimos acima, o corpo do tradutor/intérprete intermodal constitui-se como língua durante a sinalização. E, consequentemente, são demandadas habilidades singulares para lidar com o processo comunicativo e interpretativo que tem a língua de sinais como língua fonte e a língua oral como alvo (vocalização) ou, por outro lado, a língua oral como língua fonte e a língua de sinais como alvo (sinalização). Essas habilidades envolvem inclusive aspectos sociais, culturais e históricos que caracterizam e definem as comunidades surdas como minorias linguísticas e culturais que estão em processo de reconhecimento, visibilização e valorização.

Além disso, as competências, os conhecimentos, as habilidades e/ou as capacidades relacionadas aos aspectos psicofisiológicos e à gestão eficiente do processo tradutório (controle do processo, integração de seus componentes e compensação de possíveis limitações) também serão marcados, de uma forma ou de outra, pela modalidade das línguas envolvidas durante a tradução/interpretação. Isso decorre do impacto das propriedades gestuais, espaciais e visuais das línguas de sinais sobre o tradutor/intérprete e o seu desempenho, assim como sobre o próprio desdobrar do processo tradutório/interpretativo.

Todavia, é possível afirmar, de maneira geral, que aqueles componentes relacionados aos conhecimentos extralinguísticos, sejam eles culturais, enciclopédicos, temáticos, profissionais ou específicos, assim como às habilidades de manipulação de documentação e ao uso de tecnologias, não sofrerão, numa primeira e rápida avaliação, significativos impactos da modalidade de língua, já que não estão diretamente submissos às especificidades das línguas de trabalho do tradutor/intérprete ou à modalidade que as caracteriza. 
Rodrigues (2013a), por meio de uma pesquisa empírico-experimental sobre a interpretação simultânea para a língua de sinais, demonstra que quanto mais os tradutores e intérpretes experientes exploram as propriedades gestuais, espaciais e visuais das línguas de sinais maiores são suas possibilidades de maximização da semelhança interpretativa. A partir das análises apresentadas por ele, é possível depreender que a expertise em tradução/interpretação intermodal está balizada pelas habilidades de se lidar com a modalidade gestual-visual e com seus efeitos sobre a língua.

Em relação às propostas de Gonçalves (2005) e de Alves e Gonçalves (2007), temos que a competência tradutória específica $(\mathrm{CTe})$, orientada pelo princípio de Relevância, será diretamente afetada pela modalidade, visto que compreende uma competência pragmática interlingual, uma especialização do dispositivo dedutivo previsto na Teoria da Relevância, como destaca (GONÇALVES, 2008, p. 129). Ao abordar a interpretação para a língua de sinais, Rodrigues (2013a) afirma que a atribuição de semelhança interpretativa entre línguas de diferentes modalidades requer habilidades para lidar com a modalidade gestual-visual, visto que "quanto mais são explorados os dispositivos linguísticos específicos da língua de sinais maiores são as possibilidades de maximização da semelhança interpretativa". (p. 228, grifos do autor).

Em suma, uma possível competência tradutória intermodal relaciona-se ao desenvolvimento de conhecimentos e habilidades necessários tanto à exploração corporal dos dispositivos linguísticos específicos das línguas de sinais, durante a sinalização (babilidades corporais motoras de codificação integrada de propriedades gestuais e espaciais), quanto à capacidade visual-cognitiva de ler a totalidade das informações gestuais e espaciais, as quais estão expressas quadridimensionalmente por meio da integração desses dispositivos linguísticos específicos, durante a vocalização (babilidades visuais de percep̧ção e interpretação do conjunto de informações gestual e espacialmente codificadas), ambas vinculadas à habilidade de se administrar a possibilidade de sobreposição das línguas de maneira vantajosa.

\section{CONSIDERAÇÕES FINAIS}

Nessa reflexão inicial, buscamos demonstrar que as investigações sobre a competência tradutória, enquanto um fator de distinção entre bilíngues não tradutores e tradutores, apontam diversas possibilidades de se pensar os constituintes desse tipo específico de competência, sua integração, seu funcionamento, seu desenvolvimento e sua aquisição. Vimos que distintas perspectivas e visões têm 
sustentado, no decorrer das últimas décadas, principalmente no contexto Europeu, diferentes propostas e modelos de competência tradutória, os quais evidenciam posturas teóricas e balizam, inclusive, ações didáticas e pedagógicas voltadas à formação de futuros tradutores/intérpretes.

Além disso, os modelos componenciais apresentados estão basicamente voltados à representação de uma competência tradutória geral e, na maioria dos casos, estão ancorados numa visão restrita à tradução escrita. Assim, eles deixam espaço para se pensar em diferentes tipos de competência(s) tradutória(s) específica(s), já que a complexidade e a heterogeneidade, por exemplo, caracterizam e confirmam a diversificação da(s) competência(s) tradutória(s). Além disso, é possível pensar que os aspectos históricos, culturais e situacionais que envolvem os tradutores e os intérpretes e seu campo de atuação profissional também impactam, de alguma maneira, a competência tradutória requerida.

A partir dessa reflexão, poderíamos dizer que uma mera adjetivação da competência tradutória, que deixa de ser somente "interlinguística" para se tornar "intermodal", não esclarece o que de fato seria singular em relação aos conhecimentos, às habilidades, às atitudes e aos valores necessários, exclusivamente, aos tradutores e aos intérpretes intermodais quando comparados aos demais, nesse caso aos intramodais vocais-auditivos. De fato, fazem-se necessários estudos empíricos sobre o caráter da competência tradutória intermodal geral no intuito de melhor descrevê-la e, assim, poder contrastá-la às diferentes visões e modelos que se tem de competência tradutória e, com base nessa competência geral, derivar possíveis competências intermodais específicas.

A despeito disso, é possível verificar que a modalidade gestual-visual, ao ter efeitos sobre a língua de sinais, afeta necessariamente os processos tradutórios e interpretativos intermodais e, também, intramodais gestuais-visuais, ao requerer certa capacidade corporal cinestésica atrelada à competência linguística e à comunicativa. Nesse sentido, um modelo de competência tradutória geral, que se coloque acima da modalidade das línguas, demanda algum tipo de componente capaz de marcar a possibilidade de que ocorram efeitos de modalidade sobre os diferentes componentes da competência tradutória, assim como sua provável interferência na interação entre esses componentes.

Seguindo esse mesmo raciocínio, um modelo específico de competência intermodal também precisa dar conta do impacto da modalidade de língua sobre a competência do tradutor, destacando, no mínimo, algum traço ou componente distintivo relacionado às babilidades corporais motoras de codificação integrada de propriedades gestuais e espaciais e, também, às babilidades visuais de interpretação do conjunto de informações 
gestual e espacialmente codificadas, as quais se vinculam a uma determinada capacidade corporal cinestésica diretamente ligada à competência linguística e à competência comunicativa.

Por fim, diante das reflexões aqui iniciadas, considero que a questão da modalidade de língua em relação à definição e à modelagem da competência tradutória intermodal é uma questão extremamente complexa e, ao mesmo tempo, relevante, já que as investigações nesse âmbito podem contribuir significativamente à melhor compreensão do que constituiria uma competência tradutória "universal" e, mais estritamente, do que comporia a competência dos tradutores e dos intérpretes de línguas de sinais. Some-se a isso o fato de que novas pesquisas empíricas, inclusive no contexto latino-americano, podem favorecer o aperfeiçoamento dos processos formativos, também de profissionais intermodais - tradutores, intérpretes e guiaintérpretes - diante de sua atuação marcada pelas constantes transformações da cultura, da tecnologia e do mercado.

\section{REFERÊNCIAS BIBLIOGRÁFICAS}

ALVES, F. (1996). Veio-me um 'click' na cabeça: The theoretical foundations and the design of a psycholinguistically oriented, empirical investigation on German-Portuguese translation process. Meta, Montreal, v. 41, n. 1, pp. 33-44, mar. 1996. Disponível em: $<$ https://www.erudit.org/en/journals/meta/1996-v41-n1-meta180/001881ar.pdf>. Acesso em 10 ago. 2017.

ALVES, F. (2005a). Ritmo Cognitivo, meta reflexão e experiência: parâmetro de análise processual no desempenho de tradutores novatos e experientes. In: ALVES, F., MAGALHÃES, C., PAGANO, A. (Orgs.) Competência em Tradução: cognição e discurso. Belo Horizonte: Editora UFMG, pp.109-172.

ALVES, F. (2005b). Esforço cognitivo e efeito contextual em tradução: relevância no desempenho de tradutores novatos e expertos. Revista Linguagem em (Dis)curso LemD, Tubarão, v.5, pp.11-31, (número especial). Disponível em: <http://www. portaldeperiodicos.unisul.br/index.php/Linguagem_Discurso/article/view/278>. Acesso em 26 ago. 2017.

ALVES, F. (2015). Bases epistemológicas e paradigmáticas para pesquisas empíricoexperimentais sobre competência tradutória: uma reflexão crítica. D.E.L.T.A., 31-especial, pp.283-315. Disponível em: <http://www.scielo.br/scielo. php? script $=$ sci_arttext\&pid $=$ S0102-44502015000300012\&lng $=$ en\&nrm $=$ iso $>$. Acesso em 10 Jun. 2017. 
ALVES, F., GONÇALVES, J. L. V. R. (2003). A relevance-theoretic oriented approach to the investigation of inferential processes in translation. In: ALVES, F. (Ed.). Triangulating translation: perspectives in process oriented research, Amsterdam: John Benjamins, v.45, pp.3-24.

ALVES, F.; GONÇALVES, J. L. V. R. (2007). Modelling translator's competence: relevance and expertise under scrutiny. In: GAMBIER, Y.; SCHELENSIGER; M.; STOLZE, R. (Eds.). Translation studies: doubts and directions. Amsterdam: John Benjamins, pp.41-55.

ALVES, F.; MAGALHÃES, C.; PAGANO, A. (2000). Traduzir com autonomia: estratégias para o tradutor em formação. São Paulo: Contexto.

ALVES, F.; MAGALHÃES, C. (2004). Using small corpora to tap and map the process product interface in translation. TradTerm, v. 10, n. 1, pp. 179-212. Disponível em: $<$ https://www.revistas.usp.br/tradterm/article/view/47162>. Acesso em 20 jul. 2017. doi:http://dx.doi.org/10.11606/issn.2317-9511.tradterm.2004.47162.

BASQUE, J. (2015). Le concept de compétences: Quelques définitions. Montréal, Canada: Projet MAPES (Modélisation de l'approche-programme en enseignement supérieur), Réseau de l'Université du Québec. Accessible en ligne sur le Portail de soutien à la pédagogie universitaire du réseau de l'Université du Québec. Disponível em: $<$ http://pedagogie.uquebec.ca>. Acesso em 25 de nov. de 2017.

BELL, R. T. (1991). Translation and Translating. London/New York: Longman.

BRITO, L. F. (1995). Por uma gramática de língua de sinais. Rio de Janeiro: Tempo Brasileiro.

COSTELLO, B. D. N. (2015). Language and modality: Effects of the use of space in the agreement system of Lengua de Signos Española (Spanish Sign Language). Tese de Doutorado. University of Amsterdam and University of the Basque Country. Disponível em: <https://pure.uva.nl/ws/files/2569681/168517_Brendan_Costello_ thesis_complete.pdf $>$. Acesso em 10 jun. 2016.

ELMAN, J. et al. (1996). Retbinking innateness: a connectionist perspective on development. Cambridge: MIT.

GONÇALVES, J. L. V. R. (2005). O desenvolvimento da competência do tradutor: em busca de parâmetros cognitivos. In: ALVES, F., MAGALHÃES, C., PAGANO, A. (Eds.) Competência em tradução: cognição e discurso, Belo Horizonte: Editora da UFMG, pp.59-90. 
GONÇALVES, J. L. V. R. (2008). Rediscutindo o conceito de competência de uma perspectiva relevantista. In: CAMPOS, J.; RAUEN, F. J. (Orgs.). Tópicos em Teoria da Relevância. Porto Alegre: EDIPUCRS, pp. 122-142.

GUTT, E. A. (2000). Translation and relevance: cognition and context. (ed. aum. rev.) Manchester: Saint Jerome.

HATIM, B.; MASON, I. (1997). The Translator as Communicator. London/New York: Routledge.

HOHENBERGER, A.; HAPP, D.; LEUNINGER, H. (2004). Modality-dependent aspects of sign language production: evidence from slips of the hands and their repairs in German Sign Language. In: MEIER, R. P; CORMIER, K.; QUINTO-POZOS, D. Modality and structure in signed and spoken languages. Cambridge: Cambridge University Press, pp.112-142.

HURTADO ALBIR, A. (2005). A aquisição da competência tradutória: aspectos teóricos e didáticos. In: PAGANO, A.; MAGALHÃES, C.; ALVES. F. (Org.). Competência em tradução: cognição e discurso. Belo Horizonte: UFMG, pp.19-57.

HURTADO ALBIR, A. (Ed.) (2017). Researching Translation Competence by PACTE Group. Amsterdam/ Philadelphia: John Benjamins Publishing Company.

KELLY, D. (2002). Un modelo de competencia traductora: bases para el diseño curricular, Puentes, 1, p. 9-20. Disponível em: <http://wpd.ugr.es/ greti/revista-puentes/ pub1/02-Kelly.pdf>. Acesso em 15 de out. 2017.

KEY CONCEPTS. (2009). In: MUNDAY, J. (Ed.). The Routledge Companion to Translation Studies. Ed. rev. NewYork: Routledge, pp.166-240.

KLIMA, E.; BELLUGI, U. (1979). The Signs of Language. Cambridge: Harward University Press.

LOURENÇO, G. (2015). Investigando a produção de construções de interface sintáticogestual na interpretação simultânea intermodal. Cadernos de Tradução, Florianópolis, v. 35, n. 2, p. 319-353, out. 2015. Disponível em: < https://periodicos.ufsc.br/index. php/traducao/article/view/2175-7968.2015v35nesp2p319/30774>. Acesso em 27 mai. 2016.

MALMKJÆR, K. (2009). What is translation competence?, Revue française de linguistique appliquée, 2009/1, v. XIV, pp. 121-134. Disponível em: <https://www.cairn.info/ 
revue-francaise-de-linguistiqueappliquee-2009-1-page-121.htm $>$. Acesso em 10 dez. 2017.

MCBURNEY, S. L. (2004). Pronominal reference in signed and spoken language: are grammatical categories modality-dependent? In: MEIER, R. P; CORMIER, K.; QUINTO-POZOS, D. Modality and structure in signed and spoken languages. Cambridge: Cambridge University Press, pp.329-369.

MEIER, R. P. (2004). Why different, why the same? explaining effects and non-effects of modality upon linguistic structure in sign and speech. In: MEIER, R. P; CORMIER, K.; QUINTO-POZOS, D. Modality and structure in signed and spoken languages. Cambridge: Cambridge University Press, pp.1-25.

MEIER, R. P; CORMIER, K.; QUINTO-POZOS, D. (2004) Modality and structure in signed and spoken languages. Cambridge: Cambridge University Press.

METZGER, M.; QUADROS, R. M. (2012). Cognitive Control in Intermodal Bilingual Interpreters. In: QUADROS, R. M.; FLEETWOOD, E.; METZGER, M. Signed Language Interpreting in Brazil. Washington D.C.: Gallaudet University Press, pp. 43-56.

NEUBERT, A. (2000). Competence in language, in languages, and in translation. In: SCHÄFFNER, C.; ADAB, B. (Eds.). Developing Translation Competence. Amsterdam/ Philadelphia: John Benjamins Publishing Company, pp.3-18.

NOGUEIRA, T. C. (2016). Intérpretes de libras-português no contexto de conferência: uma descrição do trabalho em equipe e as formas de apoio na cabine. In: Anais $V$ Congresso Nacional de Pesquisas em Tradução e Interpretação de Libras e Língua Portuguesa. Florianópolis: PGET-UFSC, pp. 01-17. Disponível em: < http://www.congressotils. com.br/anais/2016/3334.pdf $>$. Acesso em 02 de set. 2017.

PACTE. (2001). La competencia traductora y su adquisición. Quaderns. Revista de Traducció, n. 6, pp.39-45.

PACTE. (2003). Building a translation competence model. In: ALVES, F. (Ed.). Triangulating translation: perspectives in process oriented research. Amsterdam: John Benjamins, pp.43-66.

PADDEN, C. A. (2000). Simultaneous Interpreting across modalities. Interpreting. n.5, v.2, 2000/01, pp.169-185. 
PYM, A. (2003). Redefining Translation Competence in an Electronic Age. In Defence of a Minimalist Approach. Meta: Translators' Journal, v. 48, n. 4, pp. 481-497

QUER, J. et al. (2017). SignGram Blueprint: A Guide to Sign Language Grammar Writing. Berlin/Boston: De Gruyter Mouton.

QUADROS, R. M. (2006). Efeitos de Modalidade de Língua: as Línguas de Sinais. ETD Educação Temática Digital, Campinas, v.7, n.2, p.168-178, jun. 2006. Disponível em: $<$ http://periodicos.sbu.unicamp.br/ojs/index.php/etd/article/view/801>. Acesso em 15 dez. 2015.

QUADROS, R. M.; KARNOPP, L. B. (2004). Lingua de Sinais Brasileira: estudos lingüísticos. Porto Alegre: ARTMED.

QUADROS, R. M.; SOUZA, S. X. (2008). Aspectos da tradução/ encenação na língua de sinais brasileira para um ambiente virtual de ensino: práticas tradutórias do curso de Letras Libras. In: QUADROS, R. M. (Org.). Estudos Surdos III. Petrópolis: Editora Arara Azul, v. III, pp. 170-209.

RODRIGUES, C. H. (2011). Da Margem ao centro: preparando um novo campo de debate e reflexão. Revista da Federação Nacional de Educação e Integração dos Surdos - Feneis, Rio de Janeiro, n. 42. p. 30-34, dez./fev.

RODRIGUES, C. H. (2012). Efeitos de Modalidade no Processo de Interpretação Simultânea para a Língua de Sinais Brasileira. Revista Virtual de Estudos da Linguagem, v. 10, pp. 93-124. Disponível em: <http://www.revel.inf.br/files/29427f4a35369eface ef76fadbd57b2d.pdf>. Acesso em 10 ago. 2017.

RODRIGUES, C. H. (2013a). A interpretação para a Lingua de Sinais Brasileira: efeitos de modalidade e processos inferenciais. Tese de Doutorado. Universidade Federal de Minas Gerais. Belo Horizonte. Disponível em: < http://www.bibliotecadigital.ufmg.

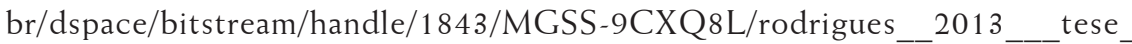
poslin.pdf? sequence $=1>$. Acesso em 10 mar. 2017 .

RODRIGUES, C. H. (2013b). A interpretação simultânea entre línguas e modalidades. Veredas (UFJF. Online), v. 17, pp. 266-286. Disponível em: < http://www.ufjf.br/ revistaveredas/files/2014/04/14\%C2\%BA-ARTIGO.pdf>. Acesso em 05 ago. 2016.

RODRIGUES, C. H. (2013c). Aspectos processuais na interpretação simultânea para a Língua de Sinais Brasileira. In: QUADROS, R. M.; STUMPF, M. R.; LEITE, T. A. 
(Org.). Estudos da Língua Brasileira de Sinais I. 1ed. Florianópolis: Insular, v. 1, pp. 195 229.

RODRIGUES, C. H.; QUADROS, R. M. (2015). Diferenças e Linguagens: a visibilidade dos ganhos surdos na atualidade. Revista Teias, [S.1.], v. 16, n. 40, p. 72-88, mar. 2015. Disponível em: <http://www.e-publicacoes.uerj.br/index.php/revistateias/article/ view/24551/17531>. Acesso em 04 mar. 2016.

RODRIGUES, C. H.; MEDEIROS, D. V. (2016). O uso de mouthing na interpretação simultânea para a Língua Brasileira de Sinais. In: $V$ Congresso Nacional de Pesquisa em Tradução e Interpretação de Lingua de Sinais Brasileira, Universidade Federal de Santa Catarina, Florianópolis, pp.1-15. Disponível em: < http://www.congressotils.com. br/anais/2016/3604.pdf>. Acesso em 10 abr. 2017.

ROTHE-NEVES, R. (2007). Notes on the concept of translator's competence. Quaderns. Revista de Traducció, v. 14, pp. 125-138.

SEGALA, R. R.; QUADROS, R. M. (2015). Tradução intermodal, intersemiótica e interlinguística de textos escritos em Português para a Libras oral. Cadernos de Tradução, Florianópolis, v. 35, n. 2, p. 354-386, out. 2015. Disponível em: < https:// periodicos.ufsc.br/index.php/traducao/article/view/2175-7968.2015v35nesp2p354 >. Acesso em 13 out. 2016.

SOUZA, S. X. (2010). Performances de tradução para a língua brasileira de sinais observadas no curso de letras-libras. Mestrado em Estudos da Tradução. Universidade Federal de Santa Catarina, Florianópolis.

SPERBER, D.; WILSON, D. (1995). Relevance, communication and Cognition. 2.ed. London: Blackwell.

STOKOE, W. C. (1960). Sign language structure: An outline of the communication systems of the American deaf. Studies in Linguistics, Occasional Papers, 8. Silver Spring, MD: Linstok Press.

SILVÉRIO, C. C. P. et al. (2012). Reflexões sobre o processo de tradução-interpretação para uma língua de modalidade espaço-visual. In: Anais - III Congresso Nacional de Pesquisas em Tradução e Interpretação de Libras e Língua Portuguesa. Florianópolis: PGET-UFSC, pp. 01-07.

WURM, S. (2010). Translation across Modalities: The Practice of Translating Written Text into Recorded Signed Language. An Ethnographic Case Study. Doutorado em 
Filosofia, Heriot-Watt University, Department of Languages and Intercultural Studies. Disponível em: < http://www.ros.hw.ac.uk/bitstream/handle/10399/2407/ WurmS_1010_sml.pdf? sequence $=1$ \&isAllowed=y $>$. Acesso em 10 mai. 2015.

Recebido: $31 / 01 / 2018$

Aceito: 04/03/2018 